\title{
The art of seeing science
}

\section{Leonardo}

by Martin Kemp

Oxford University Press: 2004. 304 pp.

$\mathfrak{1 4}$.99, \$26

\section{Stefano Grillo}

The poet Paul Valéry once described the impression created by Leonardo da Vinci's notebooks. At first glance it seems that Leonardo wrote about "the most varied subjects depending on his mood and the contingencies of the day", by working "at the service, in turn, of each of his numerous Muses”. In most of the pages of Leonardo's notes, illuminating remarks on engineering, the sciences and the visual arts lie scattered, with no apparent order, among drawings, sketches and simple information about his daily life. So the first question to ask about Leonardo's work is whether it should be treated as myriad unrelated fragments, or whether this multiplicity is articulated by a method, giving it an internal unity. What was the relationship, if any, between Leonardo's art and his science?

Early authors, including his sixteenthcentury biographer Giorgio Vasari, implied that Leonardo's excessive interest in science distracted him from his work as an artist. They thought this was why he created so few paintings, most of which he notoriously

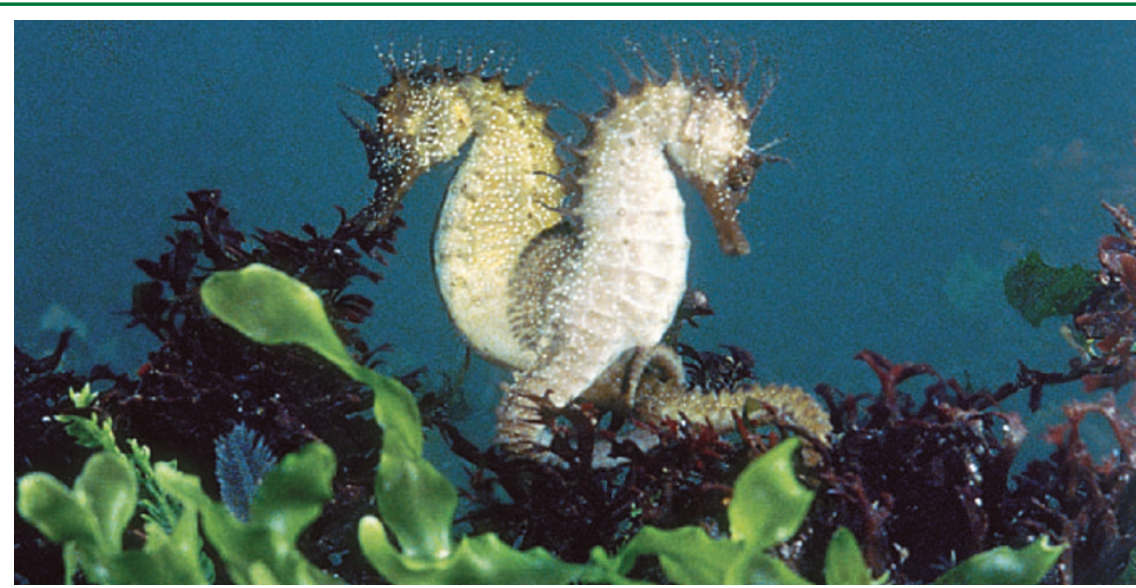

Film

\section{The story of life}

After the international success - both artistic and commercial - of their documentary film Microcosmos, about the world of insects, French directors Claude Nuridsany and Marie Pérennou now present the history of the Universe in Genesis, released in cinemas in France and Germany in October.

From the Big Bang to the first simple and ordered forms of life, and then more complex creatures emerging from the ocean, the left unfinished. At the end of the nineteenth century, a different picture emerged. Valéry, like his contemporary Gabriel Séailles (a professor of philosophy from Paris), insisted that there was a unifying method in his thought, despite the outward appearance of the notebooks. Leonardo's painting grew directly out of his understanding of nature. His works of art look so real and alive precisely because they were based on an understanding of the laws that govern natural phenomena. To draw a deluge, for example, Leonardo used his many observations of water flow and his thoughts on fluid dynamics to create one on paper, on nature's own terms. Science, far from being detrimental to his art, was as relevant to it as it was to the design of his machines.

This conception of Leonardo is at the core of Martin Kemp's new book, which the author describes as dealing with why "the Mona Lisa and the flying machine were, for Leonardo, the same kind of thing". Kemp has an unmatched ability to write about science and art with equal understanding, as readers of his Science in Culture contributions to Nature will be aware. This allows him to illustrate his insights into the mind of Leonardo with a series of concrete and penetrating analyses of his scientific studies and works of art. Kemp's aim is to equip the reader, through the examples he gives, with a means of fruitfully approaching Leonardo's work by always keeping in mind the unity of his thought.

Kemp's discussion of Leonardo's science

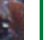

brings into relief several recurrent themes, such as his ubiquitous use of the law of proportionality, his use of geometry to grasp physical reality through visualization, and his belief in the functionality of all natural forms. At the root of Leonardo's science was the conviction that all knowledge must spring from visual observation. For Leonardo, seeing involved the intellect just as much as the eye: it was a way of using sight to penetrate natural phenomena with the mind, as magnificently demonstrated in his drawings. Kemp suggests that it is this way of 'seeing', in the sense of understanding, that makes Leonardo so fascinating today, a view I share wholeheartedly. It seems to me that whereas Galileo, the founder of the experimental method, astonishes us because we find his thinking so similar to that of the modern, mathematically based sciences, Leonardo fascinates us precisely because he understood nature differently not in terms of predictive models, but through sight.

The picture of Leonardo that emerges in broad outline from this book is of a man who made important discoveries but was working wholly within the framework of aristotelian and medieval science. Eventually, Leonardo's empirical observations brought to light internal contradictions in these inherited systems. He became dissatisfied with them but did not propose a new framework within which he could interpret his findings. I know very few writers who have described this internal movement in Leonardo's intellectual development as clearly as Kemp does; Cesare Luporini's masterly 1953 study La mente di Leonardo is a comparison that comes to mind.

Kemp's remarkable gift of writing with great clarity about a subject that is far from simple makes this wonderful and concise volume suitable for the general reader. The tone of the book is personal, with the first and last sections reading almost as a novel. Kemp's admiration for Leonardo's intellectual integrity is evident, as is his respect for the piousness with which Leonardo devoted himself to the study of the laws of nature (which he saw as the manifestation of God's design). Throughout the book, Kemp's argument moves almost imperceptibly from one area of science to another, then from science to art and, in the final pages, from life to art in one continuous, uninterrupted flow. This perfectly mirrors Leonardo's way of thinking, his constantly seeing analogies between the most different phenomena, his "never looking at anything without thinking of something else". Kemp's style of writing is a masterly illustration of Leonardo's principle that all form should fulfil a function.

Stefano Grillo is at the University of Perpignan and PROMES/CNRS, Rambla de la Thermodynamique, Tecnosud, 66100 Perpignan, France. 